\title{
Three-year Clinical Evaluation of a Flowable and a Hybrid Resin Composite in Non-carious Cervical Lesions
}

\author{
Shisei Kubo ${ }^{a}$, Hiroaki Yokota ${ }^{b}$, Haruka Yokota ${ }^{b}$ and Yoshihiko Hayashi ${ }^{c}$
}

\author{
Address: ${ }^{a}$ Center for Clinical Education and Training, Nagasaki University Hospital, 1-7-1, \\ Sakamoto, Nagasaki 852-8588, Japan \\ b Clover Dental Clinic, 3-17-13, Shodai, Sawara-ku, Fukuoka, Japan, 812-0012, \\ Japan \\ c Division of Cariology, Department of Developmental and Reconstructive \\ Medicine, Course of Medical and Dental Sciences, Nagasaki University Graduate \\ School of Biomedical Sciences, 1-7-1, Sakamoto, Nagasaki 852-8588, Japan
}

Short title: Clinical trial of a flowable resin composite

\section{Corresponding author:}

Name: Shisei Kubo

Address: Center for Clinical Education and Training, Nagasaki University Hospital, 1-7-1, Sakamoto, Nagasaki 852-8588, Japan

Phone: $\quad 81-95-819-7757$

Fax: $\quad 81-95-819-7757$

E-mail: kubo@net.nagasaki-u.ac.jp

\section{Keywords:}

Randomized controlled trial; Flowable resin composite; Hybrid resin composite; All-in-one; Non-carious cervical lesions 


\title{
Three-year Clinical Evaluation of a Flowable and a Hybrid Resin \\ Composite in Non-carious Cervical Lesions
}

\begin{abstract}
Objectives: This randomized controlled clinical trial evaluated the 3-year clinical performance of a hybrid (Clearfil AP-X; AP) and a flowable (Clearfil Flow FX; FX) resin composite in 98 non-carious cervical lesions.
\end{abstract}

Methods: Twenty-two patients, 11 male and 11 female (mean age: 61.9 years, range: 29-78 years) regularly visiting the Nagasaki University Hospital, participated in the study. Each patient received both materials randomly. All restorations (48 restorations for AP and 50 restorations for FX) were placed in conjunction with an all-in-one system (Clearfil $\mathrm{S}^{3}$ Bond) by one dentist. The restorations were blindly evaluated by two examiners at baseline, 6 months, 1, 2 and 3 years using modified USPHS criteria. The data were statistically analyzed using the Cochran's Q test and Fisher's exact test.

Results: All the patients were examined at each recall. However, five restorations could not be evaluated at 3-year recall as two teeth had been extracted and three restorations had been lost. The only minor problem was the integrity of the enamel margin. The incidence and extent of marginal staining increased with time, but it was still superficial. Marginal staining occurred adjacent to 11 restorations for AP and 12 restorations for FX after 3 years. Neither 
lesion size nor depth had influence on marginal staining adjacent to each type of resin composite. There were no significant differences in the clinical performances between AP and FX for each variable.

Conclusions: Under the protocol used in this study, both types of resin composite in conjunction with $\mathrm{S}^{3}$ Bond demonstrated an acceptable clinical performance up to 3 years. 


\section{Introduction}

Flexure at the cervical region caused by parafunctional forces has been thought to be one of the etiological factors in non-carious cervical lesions (NCCLs). ${ }^{1}$ Earlier clinical studies $^{2,3}$ indicated that microfilled resin composites showed higher retention rates in NCCLs than hybrid resin composites. The authors speculated that the resin composites with lower elastic modulus sustained lower stresses at the adhesive interfaces generated by occlusal forces, since the resin composite was able to flex with the tooth. These findings promoted the development of flowable resin composites, created by reducing the filler content but retaining the same particle size as that of hybrid composites, and having a low modulus when set. $^{4}$ However, recent clinical studies ${ }^{5,6}$ revealed no difference in retention rates between microfilled and hybrid resin composites. This inconsistency may be due to the improvement of dentin adhesive systems.

A systematic review of clinical trials has revealed that one-step self-etch, so-called 'all-in-one' adhesive systems are not as effective as conventional three-step total-etch systems and two-step self-etch systems. ${ }^{7}$ In order to solve this problem, several newer all-in-one systems with a relatively thin adhesive layer were developed several years ago. Many laboratory studies have indicated that such all-in-one systems demonstrate comparable bond strengths to those of the two-step self-etch systems. ${ }^{8-10}$ In addition, short-term clinical studies on newer all-in-one systems showed good clinical performance. ${ }^{11-15}$ 
Despite sparse clinical data, ${ }^{16,17}$ flowable resin composites have become popular because of their good handling properties. Our laboratory study ${ }^{18}$ indicated that flowable resin composites in NCCLs restored with self-etch systems did not show any deterioration of marginal sealing under flexural load cycling. By contrast, the flowable resin composites showed more microleakage than the hybrid resin composite under thermocycling. The overall findings may raise a concern about the marginal sealing of relatively large NCCLs if they are restored with flowable resin composites in conjunction with self-etch systems. Only a well controlled clinical trial can provide the ultimate proof of clinical effectiveness.

The aim of this randomized controlled clinical trial was to evaluate the 3 -year clinical performance of two types of resin composite (hybrid and flowable) in NCCLs restored with a newer all-in-one adhesive system.

\section{Materials \& Methods}

Twenty-two patients, 11 male and 11 female (mean age: 61.9 years, range: 29-78 years) regularly visiting the Department of Conservative Dentistry, Nagasaki University Hospital, participated in the study. In order to reduce a selection bias, no consideration was given to periodontal condition or to parafunctional habits. Reasons for treatment were cervical hypersensitivity, prevention of further tooth wear and/or esthetic complaints. All patients signed a consent form that had been approved by the Ethics Committee of Nagasaki 
University School of Dentistry.

A total of 98 cervical lesions, 93 NCCLs and 5 defective cervical resin composites placed in NCCLs, was restored with an all-in-one adhesive system $\left(\mathrm{S}^{3}\right.$ Bond, Kuraray Medical, Tokyo, Japan) in conjunction with a hybrid resin composite (Clearfil AP-X, Kuraray Medical) or a flowable resin composite (Clearfil Flow FX, Kuraray Medical) by the principal investigator from May to November in 2005. Composition and mechanical properties of Clearfil AP-X (AP) and Clearfil Flow FX (FX) are listed in Table 1. All but two patients had three restorations or less for each type of resin composite. Each patient received both restorative systems. A pre-set random table was used to allocate the resin composites. The first randomly selected type of resin composite was placed into all NCCLs requiring restorations in the lowest quadrant number (according to the FDI system), and the alternative resin composite was used for the second lowest quadrant number. This method used for every other quadrant if there was at least one NCCL requiring a restoration. In case of one patient with two lesions which were located in a quadrant, one lesion was restored with AP, and the other was restored with FX. The distribution of the restorations was approximately equal except for there being more AP restorations $(n=34)$ on the left in comparison to the right $(\mathrm{n}=14)$ side as shown in Table 2.

A 1-mm bevel was prepared at the enamel margin using a high-speed, water-cooled, diamond bur. Dentin walls were lightly ground with a steel round bur at slow speed without 
local anesthesia. No retention grooves were placed. In order to secure contamination-free access to the cavity, the adjacent gingiva was retracted by an unmedicated gingival retraction cord, and the operating field was isolated with cotton rolls and a saliva ejector.

The cavities were treated with $\mathrm{S}^{3}$ Bond according to the manufacturer's instructions. $\mathrm{S}^{3}$ Bond was applied to the cavity and left for 20 seconds. The solvent was evaporated with high pressure air for about 10 seconds which also thinned the adhesive layer. The adhesive was irradiated for 10 seconds with a conventional halogen light-curing unit (New Light VL-II, GC Corp., Tokyo, Japan, output $>400 \mathrm{~mW} / \mathrm{cm}^{2}$ ). For AP, the resin composite was placed in a single increment, contoured with a hand instrument, and light-cured for 40 seconds except for three very large and/or deep lesions which were restored in two increments. For FX, the resin composite was placed in two or three increments except for small and shallow cavities. Each increment was cured for 20 seconds. The excess composite was trimmed and contoured with an ultrafine diamond bur with water coolant. The restorations were finished with ultrafine diamond points as a lap joint margin to avoid damaging surrounding tooth tissues, and polished with slow speed silicone points at a following visit at which time color photographs at 1:1 magnification were taken.

The restorations were blindly evaluated at baseline, 6 months, 1 year, 2 years and 3 years by the second and third investigators, and further 1:1 color photographs taken. Slightly modified USPHS criteria were used (Table 3). For marginal staining, the Bravo score was 
subdivided further as shown in Figure 1: (1) slight staining, (2) dark-colored localized (less than $1.5 \mathrm{~mm}$ in length) staining, (3) dark-colored linear (more than $1.5 \mathrm{~mm}$ in length) staining. In case of disagreement, a consensus was reached based on assessment of the photographs. In view of the need to observe the restorations in the future, no attempt was made to remove any visible excess by refurbishing.

Cochran's Q test was used to compare the changes across the five time points (baseline, 6 months, 1 year, 2 years and 3 years). The comparison of two types of resin composite for each category was performed with the Fisher's exact test. For all of the statistical analyses, a significant level was set at $\mathrm{p} \leq 0.05$.

\section{Results}

Although all patients were examined at 3-year recall, five out of 98 restorations could not be evaluated as two teeth had been extracted and three restorations had been lost. The clinical evaluations are summarized in Table 4. There were no significant differences in the clinical performances between $\mathrm{AP}$ and $\mathrm{FX}$ for each variable. One hundred percent retention was recorded for AP, whereas three out of 50 restorations were lost for FX. All retention failures occurred with in 6 months, and two failures were in the same patient's right mandible. No secondary caries was detected around any restorations. Two cases of gingival recession were noted adjacent to AP restorations over the 3-year study period. 
The only problem observed related to enamel marginal integrity. Small steps were detected at the margins of many restorations, regardless of the type of resin composite. However, only two and one crevices were rated Bravo for AP and FX, respectively. The incidence of marginal staining increased with time as shown in Figure 2. Marginal staining occurred adjacent to 11 restorations for AP and 12 restorations for FX after 3 years, and was significantly worse than at baseline. The extent of marginal staining still appeared to be superficial. The progress of marginal staining in typical cases for respective resin composites is displayed in Figure 3 and 4 . Interestingly, if more than two marginal stains occurred in the patient, at least one of them was associated with each type of resin composite. In addition, marginal staining was found in 11 out of 22 patients. Neither lesion size nor depth had influence on marginal staining adjacent to either type of resin composite, as presented in Table 5.

\section{Discussion}

Polymerization contraction, thermal changes and occlusal forces generate interfacial stresses which potentially cause de-bonding of a resin composite to tooth, and lead to clinical failure of the restoration. ${ }^{19}$ In addition, hydrolytic degradation of bonding and restorative materials may occur. ${ }^{20-22}$ Generally, the filler content of resin composites shows a direct correlation with the elastic modulus, whereas it has inverse correlations with the viscosity, 
volumetric polymerization shrinkage, coefficients of thermal expansion and the amount of water sorption. ${ }^{19,23-26}$ Watanabe ${ }^{25}$ reported that microleakage in cervical cavities after light activation or after flexural load cycling decreased as the filler content decreased. By contrast, the microleakage after thermocycling increased as filler content decreased. Our laboratory study ${ }^{18}$, which compared the microleakage of simulated NCCLs restored with flowable and hybrid resin composites, indicated similar results and a large role of the adhesive systems in the microleakage. Therefore, the stress development at the adhesive interface, degradation of bond strength and fatigue of restorative materials seem to be complex problems in clinical situations.

Flowable resin composites were introduced in $1996 .^{4}$ The success of the flowable resin composites was more a result of marketing than of any special properties beyond flow, which does not mean flow during polymerization but low viscosity of the unset material. ${ }^{4}$ Flowability is likely to be achieved mainly by reducing the filler loading. ${ }^{4}$ Although flowable resin composites with more than $80 \%$ filler content by weight have recently been developed $^{26}$, the filler content by weight for FX $(65 \%)$ is about $20 \%$ less than that of AP (85\%), as reported by Bayne et al. $^{4}$ Labella et al. ${ }^{19}$ revealed that the elastic moduli of flowable rein composites were in the low-medium range, while the hybrid composites showed the highest values and the microfilled the lowest. The elastic moduli of AP and FX are 16.8 $\mathrm{GPa}$ and 5.5 GPa, respectively. 
Retention of resin composites in NCCLS relies on dentin bonding and its durability since lesion shapes are usually non-retentive and macro-mechanical retention is usually not provided. In addition, Heymann et al. ${ }^{2}$ reported that factors related to tooth flexure, such as occlusal stress, patient age, restorative material and restoration location, showed associations with retention failures. Microfilled resin composites showed higher retention rates compared to hybrid resin composites when adhesive systems with low dentin bond strength were used. $^{2,3}$ The authors speculated that the resin composites with lower elastic modulus relieved the stresses at the adhesive interfaces generated by occlusal forces. A thick adhesive layer may also have a stress-breaking effect in relieving thermal and occlusal stresses as well as polymerization shrinkage. ${ }^{23,27}$ Since a relatively thin adhesive layer is a characteristic of newer all-in-one systems, the use of a flowable resin composite might be beneficial, as suggested by Peumans et al. ${ }^{6}$ In the present study, however, there was no significant difference in retention rates between the two types of resin composite. This finding is supported by the results of a recent clinical study. ${ }^{17}$ This inconsistency may be due to the improvement of dentin adhesive systems, though the magnitude of dentin bond strength to prevent retention failure of a resin composite in NCCLs is still unclear. Several short-term (1-3 years in duration) clinical trials of newer all-in-one systems demonstrated almost $100 \%$ retention rates, regardless of the type of resin composite. ${ }^{11-15}$ Many studies reported that retention rates decreased with time..$^{2,16,17}$ This is probably due to fatigue failure 
of adhesives. Although three restorations had been lost at 6 months recall, no further retention failures occurred up to 3 years in the present study. A possible explanation for this is technical error rather than poor bond strength or durability of the adhesive system. Early loss of restorations may no longer be the main cause of clinical failure when reliable adhesives are used. ${ }^{6,11-15,29,30}$ In addition, delayed finishing and polishing may have some influence on good retention, since delayed polishing might be able to reduce interfacial gap formation as reported by Irie et al. ${ }^{28}$ The influence of the factors related to tooth flexure on retention can-not be determined in our study due to the small number of failures.

Marginal defects and/or marginal staining are signs of bond degradation or clinical failures. ${ }^{30}$ Repeated occlusal and thermal stresses may cause fatigue of restorative materials. Mechanical properties of flowable resin composite seem to be lower than those of hybrid resin composites as reported by Bayne et al. ${ }^{4}$ Flowable resin materials also have a higher water sorption over time due to their higher resin content ${ }^{17}$, and might have some effect on degradation of bonding and/or restorative materials. A previous clinical trial of flowable resin composites demonstrated a significantly poorer marginal adaptation after 2 years clinical service compared to a hybrid resin composite. ${ }^{17}$ However, the present study showed no significant difference in marginal adaptation. A possible explanation for this is that different adhesive systems were used. Most self-etch adhesives are likely to show lower bond strengths to enamel, especially to uncut enamel, than etch-and-rinse systems. ${ }^{31}$ In addition, 
all-in-one adhesives may be more susceptible to hydrolytic degradation of the constituent resins due to their hydrophilic nature. ${ }^{20,22}$ Therefore, even the hybrid resin composite overlapping uncut enamel adjacent to the cavity margin may easily be fractured by the etiological forces associated with NCCLs, since fracture resistance of resin composites decreases as bond strength decreases. ${ }^{32,33}$ This is supported by the results of clinical trials. $^{11,12,14,30}$ Another possible explanation is that the evaluation criterion for marginal adaptation is subjective. In this study, the criterion for marginal adaptation was modified to be generous as reported by our previous study. ${ }^{15}$ As a result, no difference in marginal adaptation between the flowable and the hybrid resin composites could be found. This may be also responsible for better marginal adaptation compared to other studies. ${ }^{11,12,14}$

The frequency of marginal staining at 1 year $(16.7 \%$ for AP, $10 \%$ for $\mathrm{FX})$ is similar to that of another clinical study (13.3\%) associated with S3 Bond. ${ }^{13}$ Marginal staining is thought to be caused by microleakage, discoloration of an exposed relatively thick adhesive layer and/or retention of stains at marginal defects. Although significant decreases in bond strength to both enamel and dentin by water storage has been reported ${ }^{20,22}$, all marginal staining but one occurred at the enamel margins. The relationship between marginal staining and marginal adaptation was indicated in previous studies. ${ }^{15,29,30}$ Approximately $70 \%$ of marginal staining occurred at the mesial and/or distal margins of the restoration, where it is difficult to access during finishing of the restoration. Burrow and Tyas ${ }^{13}$ also reported 
similar findings. Therefore, marginal staining was probably caused by the accumulation of stains at the marginal steps or crevices rather than microleakage, which is consistent with other studies. ${ }^{14,15,29}$ This may also explain the reason for the lack of influence of lesion size and depth on marginal staining. However, not all the marginal defects resulted in marginal staining. ${ }^{11,14,29,30}$ Patient related factors such as preference of food and beverage, smoking and tooth-brushing habits seem to play a role in marginal staining. ${ }^{13,15}$ More long-term study is required to obtain definitive information about clinical effectiveness of the flowable resin composite and the newer all-in-one adhesive system.

\section{Conclusion}

Under the protocol used in this study, there were no significant differences in the clinical performance between the two types of resin composite. In addition, $\mathrm{S}^{3}$ Bond provided acceptable clinical performance after 3 years of clinical service, although about $23 \%$ of the restorations had slight marginal staining. 


\section{References}

1. Lee WC \& Eakle WS. Possible role of tensile stress in the etiology of cervical erosive lesions of teeth. Journal of Prosthetic Dentistry 1984; 52: 374-380.

2. Heymann HO, Sturdevant JR, Bayne S, Wilder AD, Sluder TB \& Brunson WD. Examining tooth flexure effects on cervical restorations: A two-year clinical study. Journal of the American Dental Association 1991; 122: 41-47.

3. Van Meerbeek B, Braem M, Lambrechts P, Vanherle G. Evaluation of two dentin adhesives in cervical lesions. Journal of Prosthetic Dentistry 1993; 70: 308-314.

4. Bayne SC, Thompson JY, Swift EJ Jr, Stamatiades P, Wilkerson M. A characterization of first-generation flowable composites. Journal of the American Dental Association 1998; 129: $567-577$.

5. Browning WD, Brackett WW, Gilpatrick RO. Two-year clinical comparison of a microfilled and a hybrid resin-based composite in non-carious class V lesions. Operative Dentistry 2000; 25: 46-50.

6. Peumans M, De Munck J, Van Landuyt KL, Kanumilli P, Yoshida Y, Inoue S, Lambrechts P, Van Meerbeek B. Restoring cervical lesions with flexible composites. Dental Materials 2007; 23: 749-754.

7. Peumans M, Kanumilli P, De Munck J, Van Landuyt K, Lambrechts P, Van Meerbeek B. Clinical effectiveness of contemporary adhesives: A systematic review of current clinical 
trials. Dental materials 2005; 21: 864-881.

8. Ishikawa A, Shimada Y, Foxton RM, Tagami J. Micro-tensile and micro-shear bond strengths of current self-etch adhesives to enamel and dentin. American Journal of Dentistry 2007; 20: 161-166.

9. Sidhu SK, Omata Y, Tanaka T, Koshiro K, Spreafico D, Semeraro S, Mezzanzanica D, Sano H. Bonding characteristics of newly developed all-in-one adhesives. Journal of Biomedical Materials Research Part B; Applied Biomaterials 2007; 80: 297-303.

10. Knobloch LA, Gailey D, Azer S, Johnston WM, Clelland N, Kerby RE. Bond strengths of one- and two-step self-etch adhesive systems. Journal of Prosthetic Dentistry 2007; 97:216-222.

11. Kurokawa H, Miyazaki M, Takamizawa T, Rikuta A, Tsubota K, Uekusa S. One-year clinical evaluation of five single-step self-etch adhesive systems in non-carious cervical lesions. Dental Materials Journal 2007; 26: 14-20.

12. Ritter AV, Heymann HO, Swift Jr EJ, Sturdevant JR, Wilder Jr AD. Clinical evaluation of an all-in-one adhesive in non carious cervical lesions with different degrees of dentin sclerosis. Operative Dentistry 2008; 33: 370-378.7

13. Burrow MF, Tyas MJ. A clinical trial comparing two all-in-one adhesive systems used to restore non-carious cervical lesions: results at one year. Australian Dental Journal 2008; 53: $235-238$. 
14. Van Landuyt KL, Peumans M, Fieuws S, De Munck J, Cardoso M, Ermis R, Lambrechts P, Van Meerbeek B. A randomized controlled clinical trial of a HEMA-free all-in-one adhesive in non-carious cervical lesions at 1 year. Journal of Dentistry 2008; 36: 847-855.

15. Kubo S, Yokota H, Yokota H, Hayashi Y. Two-year clinical evaluation of one-step self-etch systems in non-carious cervical lesions. Journal of Dentistry 2009; 37: 149-155.

16. Tyas MJ, Burrow MF. Three-year clinical evaluation of One-step in non-carious cervical lesions. American Journal of Dentistry 2002; 15: 309-311.

17. Çelik Ç, Özügnaltay G, Attar N. Clinical evaluation of flowable resin in non-carious cervical lesions: Two year results. Operative Dentistry 2007; 32: 313-321.

18. Kubo S, Yokota H, Yokota H, Hayashi Y. Microleakage of cervical cavities restored with flowable composites. American Journal of Dentistry 2004; 17: 33-37.

19. Labella R, Lambrechts P, Van Meerbeek B, Vanherle G. Polymerization shrinkage and elasticity of flowable composites and filled adhesives. Dent Mater 1999; 15: 128-137.

20. Tay FR, Pashley DH. Water treeing-a potential mechanism for degradation of dentine adhesives. American Journal of Dentistry 2003; 16: 6-12.

21. Wang H, Shimada Y, Tagami J. Shear bond stability of current adhesive systems to enamel. Operative Dentistry 2004; 29: 168-175.

22. Torkabadi S, Nakajima M, Ikeda M, Foxton RM, Tagami J. Bonding durability of HEMA-free and HEMA-containing one-step adhesives to dentine surrounded by bonded 
enamel. Journal of Dentistry 2008; 36: 80-86.

23. Kemp-Scholte CM, Davidson CL. Marginal integrity related to bond strength and strain capacity of composite resin systems. Journal of Prosthetic Dentistry 1990; 64: 658-664.

24. Versluis A, Douglas WH, Sakaguchi RL. Thermal expansion coefficient of dental composites measured with strain gauges. Dental Materials 1996; 12: 290-294.

25. Watanabe T. Effect of filler content on microleakage of cervical resin composite restorations. Evaluation under flexural load cycling and thermal cycling. Japanese Journal of Conservative Dentistry 2000; 43: 308-317.

26. Lohbauer U, Frankenberger R, Krämer N, Petschelt A. Strength and fatigue performance versus filler fraction of different types of direct dental restoratives. Journal of Biomedical Materials Research Part B Applied Biomaterials 2006; 76:114-120.

27. Kubo S, Yokota H, Yokota H, Hayashi Y. Effect of low-viscosity resin-based composite on the microleakage of cervical restorations. American Journal of Dentistry 2003; 16: 244-248.

28. Irie M, Hatanaka K, Suzuki K, Watts DC. Immediate versus water-storage performance of Class V flowable composite restoratives. Dental Materials 2006; 22: 875-883.

29. Kubo S, Kawasaki K, Yokota H, Hayashi Y. Five-year clinical evaluation of two adhesive systems in non-carious cervical lesions. Journal of Dentistry 2006; 34: 97-105.

30. Peumans M, De Munck J, Van Landuyt K, Lambrechts P, Van Meerbeek B. Five-year 
clinical effectiveness of a two-step self-etching adhesive. Journal of Adhesive Dentistry 2007; 9: 7-10.

31. Perdigão J, Gomes G, Duarte Jr S, Lopes MM. Enamel Bond strengths of pairs of adhesives from the same manufacturer. Operative Dentistry 2005; 30: 492-499.

32. Kubo S. Study on the mechanism of marginal fracture of the posterior composite resins Part 1 Relation between cavity wall adhesion of the resins and marginal fracture. Japanese Journal of Conservative Dentistry 1987; 30: 13-27.

33. Furukawa K, Inai N, Tagami J. The effects of luting resin bond to dentin on the strength of dentin supported by in direct resin composite. Dental Materials 2002; 18: 136-142. 
Table 1 Composition and mechanical properties of resin composites used in the study

\begin{tabular}{|c|c|c|c|c|}
\hline \multicolumn{2}{|l|}{ Materials } & \multirow{3}{*}{$\begin{array}{l}\text { Composition } \\
\text { Bisphenol A diglycidylmethac- } \\
\text { rylate (Bis-GMA), Triethylene- } \\
\text { glycol dimethacrylate }\end{array}$} & \multicolumn{2}{|c|}{ Mechanical properties } \\
\hline \multirow[t]{4}{*}{ Clearfil AP-X } & \multirow[t]{2}{*}{ Matrix } & & $\begin{array}{l}\text { Filler Content by } \\
\text { weight }(\%)\end{array}$ & 85 \\
\hline & & & $\begin{array}{l}\text { Elastic modulus } \\
(\mathrm{GPa})\end{array}$ & 16.8 \\
\hline & \multirow[t]{2}{*}{ Filler } & \multirow[t]{2}{*}{$\begin{array}{l}\text { Silanated barium glass, silanated } \\
\text { silica, silanated colloidal silica }\end{array}$} & $\begin{array}{l}\text { Compressive } \\
\text { strength }(\mathrm{MPa})\end{array}$ & 412 \\
\hline & & & $\begin{array}{l}\text { Flexural strength } \\
(\mathrm{MPa})\end{array}$ & 164 \\
\hline \multirow[t]{4}{*}{ Clearfil Flow FX } & \multirow[t]{2}{*}{ Matrix } & \multirow{2}{*}{$\begin{array}{l}\text { Bisphenol A diglycidylmethac- } \\
\text { rylate (Bis-GMA), Triethylene- } \\
\text { glycol dimethacrylate, Urethane } \\
\text { dimethacrylate (UDMA) }\end{array}$} & $\begin{array}{l}\text { Filler Content by } \\
\text { weight }(\%)\end{array}$ & 65 \\
\hline & & & $\begin{array}{l}\text { Elastic modulus } \\
(\mathrm{GPa})\end{array}$ & 5.6 \\
\hline & \multirow[t]{2}{*}{ Filler } & \multirow[t]{2}{*}{$\begin{array}{l}\text { Barium glass, lanthanoid fluoride, } \\
\text { others }\end{array}$} & $\begin{array}{l}\text { Compressive } \\
\text { strength (MPa) }\end{array}$ & 279 \\
\hline & & & $\begin{array}{l}\text { Flexural strength } \\
(\mathrm{MPa})\end{array}$ & 113 \\
\hline
\end{tabular}

The information was obtained from the manufacturer 
Table 2 Distribution of restorations

\begin{tabular}{|c|c|c|c|c|c|c|c|c|c|}
\hline \multirow{2}{*}{$\begin{array}{c}\text { Type of } \\
\text { resin } \\
\text { composite }\end{array}$} & \multirow{2}{*}{ Arch } & \multicolumn{4}{|c|}{ Right quadrants } & \multicolumn{4}{|c|}{ Left quadrants } \\
\hline & & Molar & Premolar & Canine & Incisor & Incisor & Canine & Premolar & Molar \\
\hline \multirow{2}{*}{ AP (48) } & Maxilla (27) & 1 & 2 & 1 & 1 & 3 & 8 & 9 & 2 \\
\hline & Mandible (21) & 0 & 7 & 1 & 1 & 5 & 2 & 5 & 0 \\
\hline \multirow{2}{*}{$\mathrm{FX}(50)$} & Maxilla (21) & 2 & 6 & 3 & 2 & 1 & 0 & 5 & 2 \\
\hline & Mandible (29) & 2 & 7 & 0 & 4 & 3 & 3 & 7 & 3 \\
\hline
\end{tabular}

( ), total number of restorations 
Table 3 Modified USPHS criteria for direct clinical evaluation

\begin{tabular}{|c|c|c|c|}
\hline \multirow{2}{*}{ Category } & \multicolumn{2}{|c|}{ Rating scale } & \multirow{2}{*}{ Criteria } \\
\hline & acceptable & unacceptable & \\
\hline \multirow[t]{2}{*}{ Retention } & A & & Retained \\
\hline & & $\mathrm{C}$ & Missing \\
\hline \multirow[t]{3}{*}{ Marginal staining } & A & & None \\
\hline & $\mathrm{B}$ & & Superficial staining (removable, localized) \\
\hline & & $\mathrm{C}$ & Deep staining (not removable, generalized) \\
\hline \multirow[t]{2}{*}{ Recurrent caries } & A & & None \\
\hline & & $\mathrm{C}$ & Present \\
\hline \multirow[t]{3}{*}{ Marginal adaptation } & A & & $\begin{array}{l}\text { Undetectable margin or slight detectable step (catches explorer } \\
\text { going one way) }\end{array}$ \\
\hline & $\mathrm{B}$ & & Detectable crevice (catches explorer going both ways) \\
\hline & & $\mathrm{C}$ & Obvious crevice or fracture \\
\hline \multirow[t]{3}{*}{ Gingival recession } & A & & None \\
\hline & $\mathrm{B}$ & & Mild recession (less than $0.5 \mathrm{~mm}$ ) \\
\hline & & $\mathrm{C}$ & Sever recession (more than $0.5 \mathrm{~mm}$ ) or recurrent non-cervical lesion \\
\hline Other failures & A & & None \\
\hline (color change, wear, etc) & & $\mathrm{C}$ & Present \\
\hline
\end{tabular}


Table 4 Direct evaluations for restorations at the 3-year recall

\begin{tabular}{|c|c|c|c|c|c|}
\hline \multirow{2}{*}{ Category } & \multirow{2}{*}{$\begin{array}{l}\text { Type of resin } \\
\text { composites }\end{array}$} & \multicolumn{2}{|c|}{ Acceptable } & \multirow{2}{*}{$\begin{array}{c}\text { Not acceptable } \\
\text { C }\end{array}$} & \multirow{2}{*}{ p-values } \\
\hline & & A & B & & \\
\hline \multirow[t]{2}{*}{ Retention } & AP & $46(100)$ & - & 0 & \multirow{2}{*}{0.243} \\
\hline & FX & 47 (94) & - & $3(6)$ & \\
\hline \multirow[t]{2}{*}{ Marginal staining } & $\mathrm{AP}$ & $35(76)$ & $11(24)$ & 0 & \multirow{2}{*}{1.000} \\
\hline & FX & 35 (74) & $12(26)$ & 0 & \\
\hline \multirow[t]{2}{*}{ Recurrent caries } & $\mathrm{AP}$ & $46(100)$ & - & 0 & \multirow{2}{*}{1.000} \\
\hline & FX & $47(100)$ & - & 0 & \\
\hline \multirow[t]{2}{*}{ Marginal adaptation } & $\mathrm{AP}$ & 44 (96) & $2(4)$ & 0 & \multirow{2}{*}{0.617} \\
\hline & FX & $46 \quad(98)$ & $1(2)$ & 0 & \\
\hline \multirow[t]{2}{*}{ Gingival recession } & AP & $43 \quad(93)$ & $1(2)$ & $2(4)$ & \multirow{2}{*}{0.489} \\
\hline & $\mathrm{FX}$ & $46 \quad(98)$ & $1(2)$ & 0 & \\
\hline Other failures & $\mathrm{AP}$ & $46(100)$ & - & 0 & \multirow{2}{*}{1.000} \\
\hline (color change, wear, etc' & FX & $47(100)$ & - & 0 & \\
\hline
\end{tabular}

( ), percent 
Table 5 The influence of lesion size and depth on marginal staining

\begin{tabular}{lcccccccccc}
\hline \multirow{2}{*}{ Depth } & \multicolumn{7}{c}{ Size } \\
\cline { 2 - 10 } & \multicolumn{2}{c}{ Small } & \multicolumn{2}{c}{ Medium } & \multicolumn{2}{c}{ Large } & & Total \\
& AP & FX & AP & FX & AP & FX & AP & FX & All \\
\hline Shallow & $2 / 9$ & $5 / 20$ & $2 / 7$ & $4 / 16$ & $0 / 1$ & $0 / 1$ & $4 / 17$ & $9 / 37$ & $13 / 54$ \\
Moderate & $0 / 1$ & $0 / 1$ & $5 / 21$ & $3 / 12$ & $2 / 4$ & $0 / 0$ & $7 / 26$ & $3 / 13$ & $10 / 39$ \\
Deep & $0 / 0$ & $0 / 0$ & $0 / 2$ & $0 / 0$ & $0 / 3$ & $0 / 0$ & $0 / 5$ & $0 / 0$ & $0 / 5$ \\
Total & $2 / 10$ & $5 / 21$ & $7 / 30$ & $7 / 28$ & $2 / 8$ & $0 / 1$ & $11 / 48$ & $12 / 50$ & $23 / 98$ \\
\hline
\end{tabular}

number of restorations with marginal staining / total number of restorations

Small $(<1 \mathrm{~mm}$ in longitudinal width); medium $(1-2.5 \mathrm{~mm})$; large $(>2.5 \mathrm{~mm})$; $\mathrm{S}$, shallow $(<0.5 \mathrm{~mm})$; M, moderate $(0.5-1.5$ $\mathrm{mm})$; D, deep $(>1.5 \mathrm{~mm})$ 
Figure 1
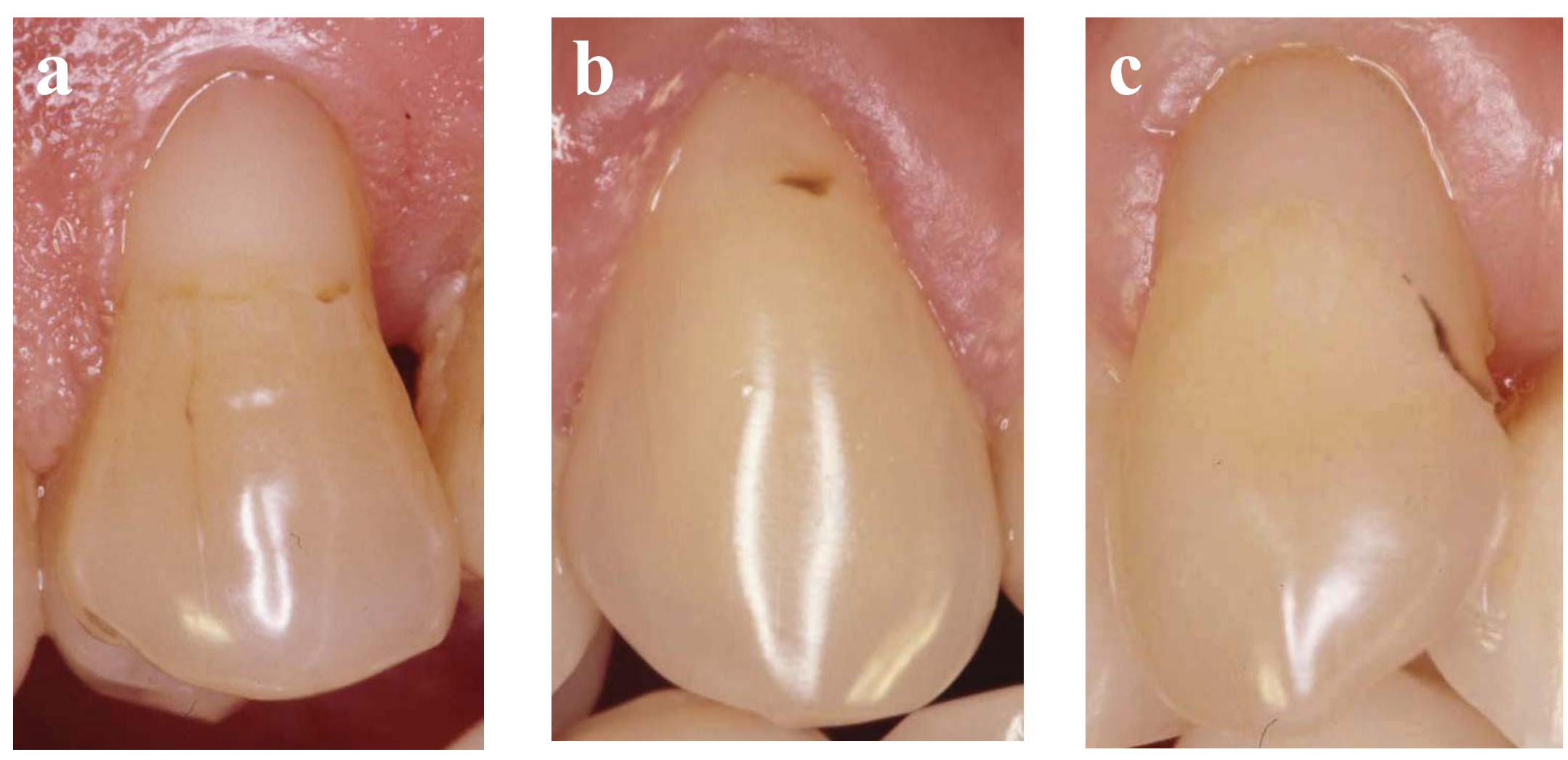
Figure 2

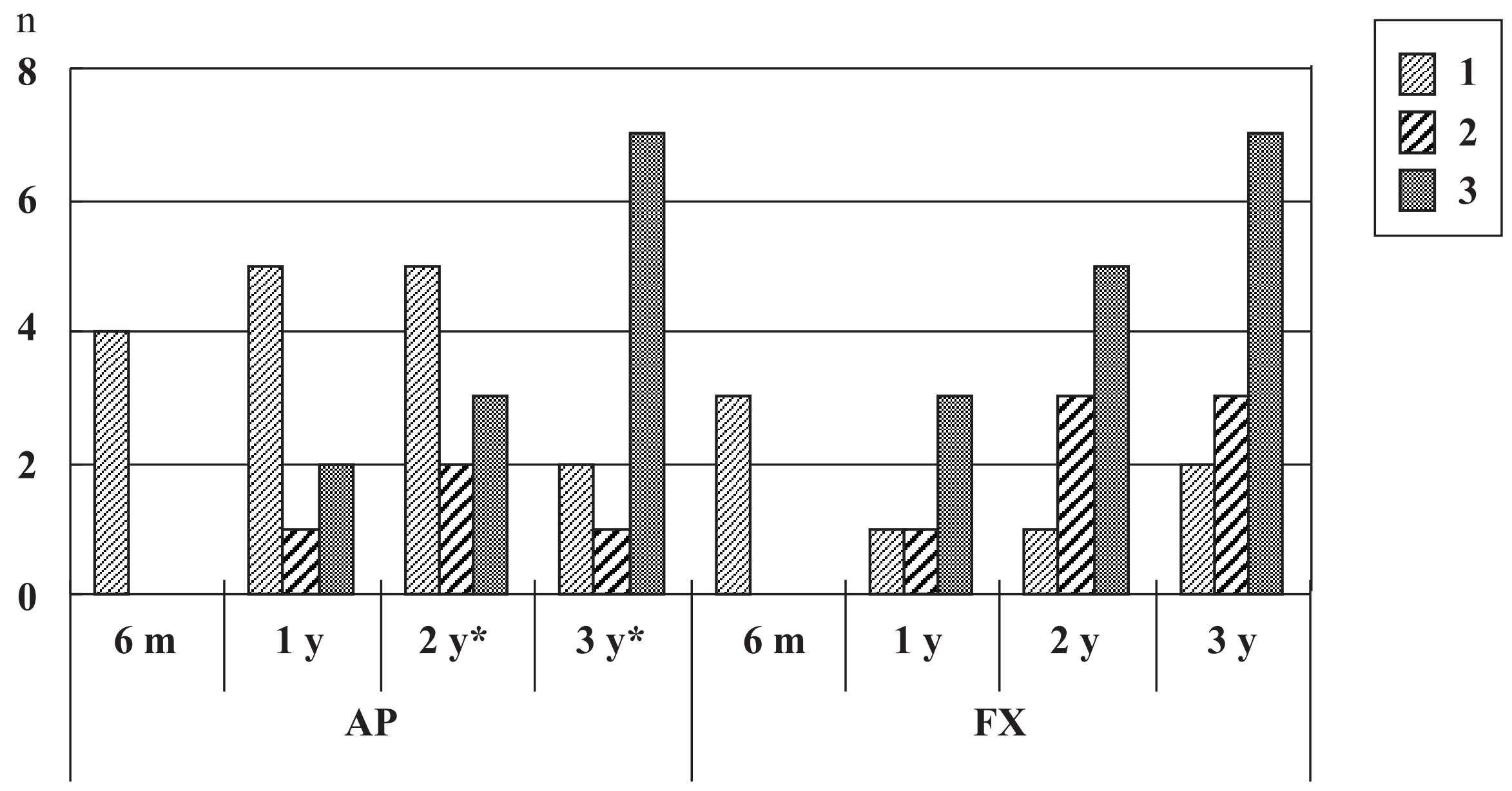


Figure 3
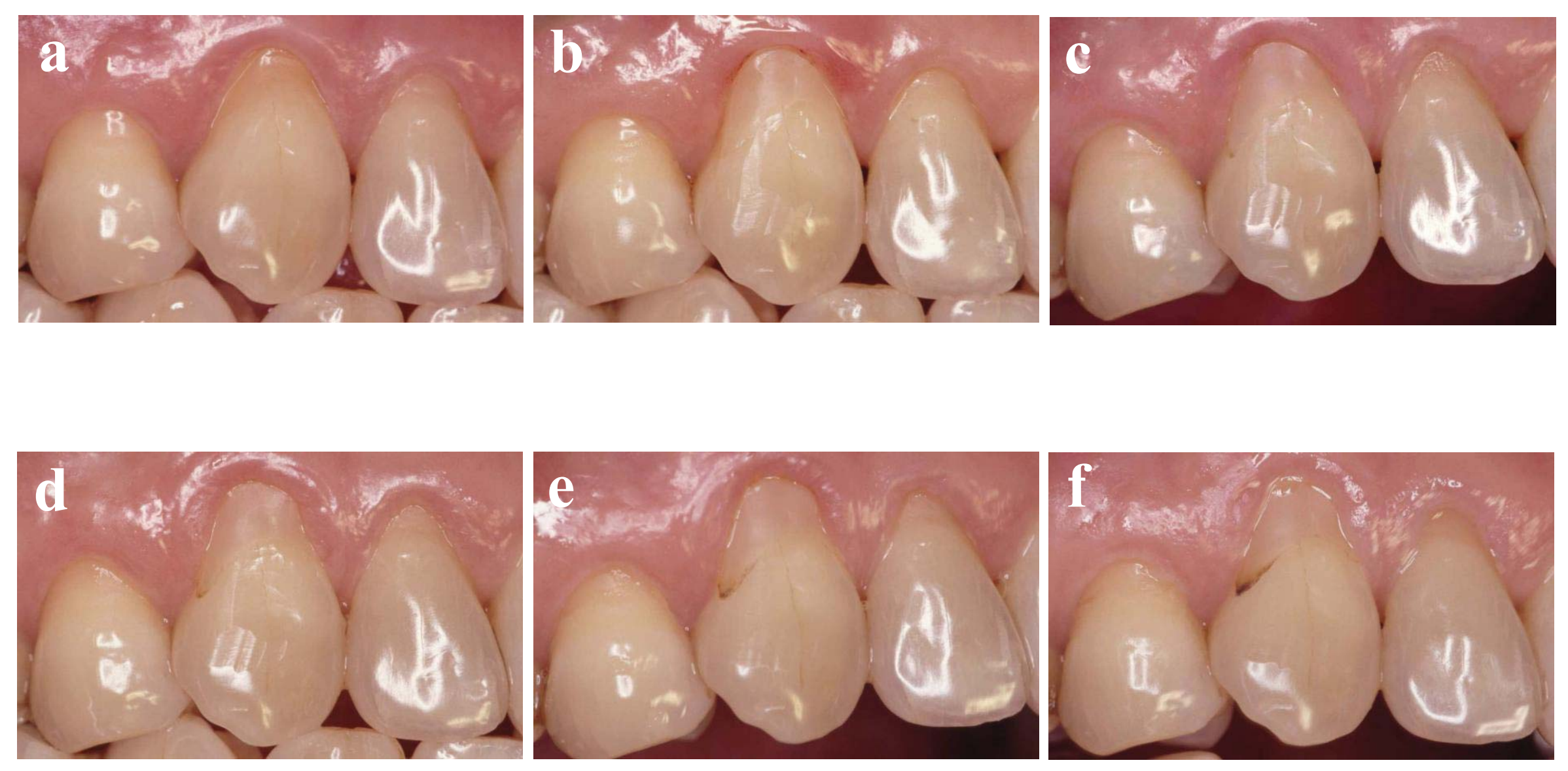
Figure 4
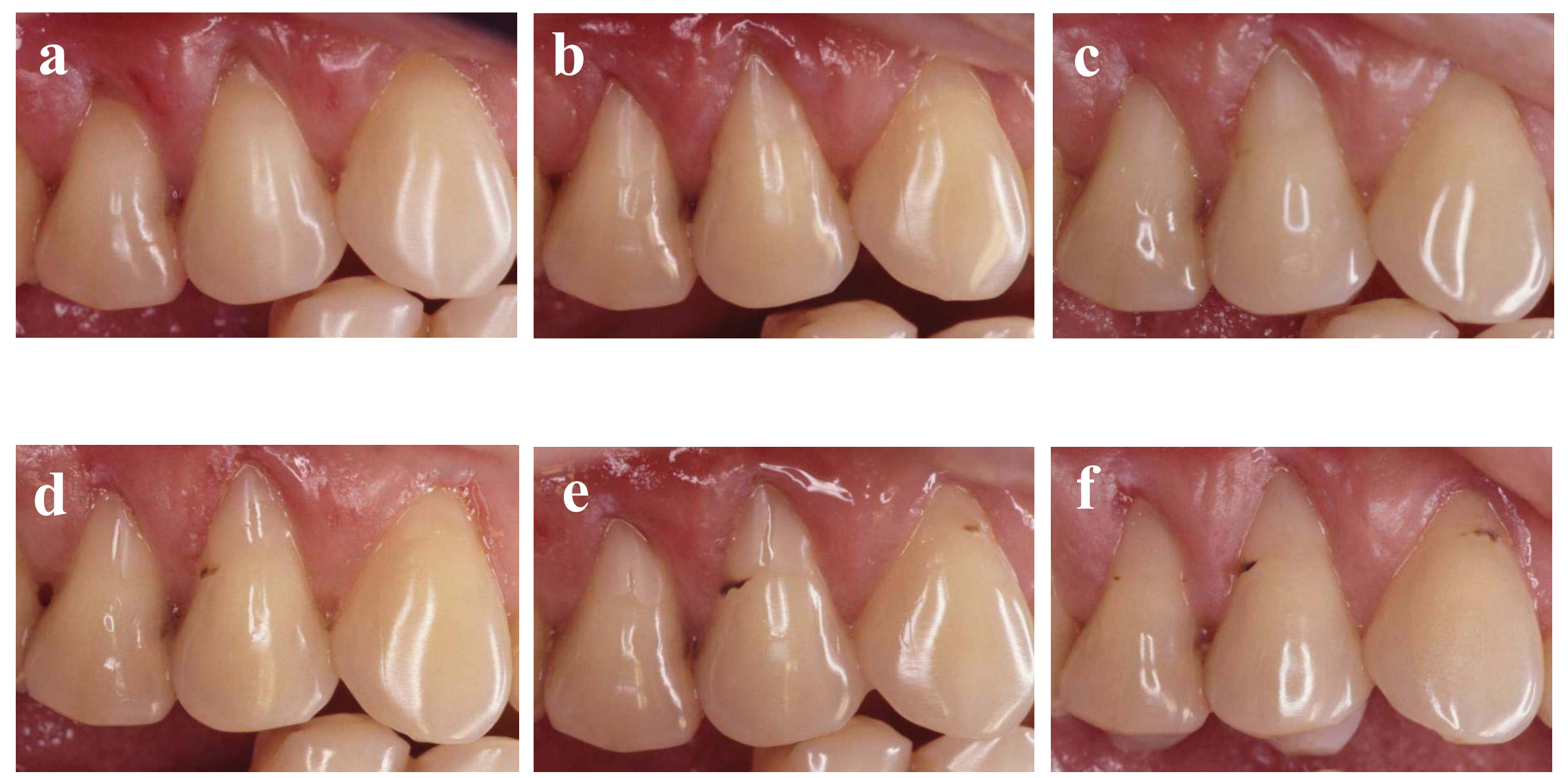


\section{Legends}

Figure 1 Subdivision of criteria for the Bravo score on marginal staining. a: slight staining (AP at 2-year recall); b: dark-colored localized (less than $1.5 \mathrm{~mm}$ in length) staining (FX at 2-year recall); c: dark-colored linear (more than $1.5 \mathrm{~mm}$ in length) staining (AP at 3-year recall).

Figure 2 The incidence and extent of marginal staining. $n$ : number of restorations which had marginal staining. 1: slight staining; 2: dark-colored localized staining; 3 : dark-colored linear staining. *: one restoration with slight marginal discoloration was extracted after 1-year recall.

Figure 3 Progress of marginal staining. Non-carious cervical lesion in canine tooth was restored with $\mathrm{S}^{3}$ Bond and AP: (a) cervical lesion (rated as medium size and moderate depth) in canine tooth; (b) baseline; (c) marginal staining was suspected at the distal margin after 6 months; (d) slight staining was visible at 1-year recall; (e) the extent of marginal staining progressed at 2-year recall; (e) linear dark-colored marginal staining was clearly visible at 3-year recall. 
Figure 4 Progress of marginal staining. Non-carious cervical lesions in canine and premolars were restored with $\mathrm{S}^{3}$ Bond and FX: (a) cervical lesions (premolars were rated as medium and shallow, canine was rated as small and shallow.); (b) baseline; (c) marginal staining was suspected at the distal margin of the first premolar after 6 months; (d) localized staining was clearly visible in the first premolar at 1-year recall; (e) the extent of marginal staining in the first premolar progressed, and clear localized staining appeared in canine at 2-year recall; (e) small but dark-colored marginal staining occurred at the distal margin of the second premolar after 3 years . 


\section{Acknowledgements}

This study was supported by Grant-in-Aid for Scientific Research from the Ministry of Education, Culture, Sports, Science and Technology of Japan (16591918 and 20592230). The authors wish to thank Prof. Martin Tyas, University of Melbourne, for assistance in preparation of the manuscript. 